CLINICAL STUDY

\title{
Insulin enhances ACTH-stimulated androgen and glucocorticoid metabolism in hyperandrogenic women
}

\author{
Flavia Tosi, Carlo Negri, Elisabetta Brun, Roberto Castello, Giovanni Faccini ${ }^{1}$, Enzo Bonora, Michele Muggeo, \\ Vincenzo Toscano ${ }^{2}$ and Paolo Moghetti \\ Division of Endocrinology and Metabolism and ${ }^{1}$ Clinical Chemistry Laboratory, University and Azienda Integrata Ospedaliera Universitaria di Verona, P.le \\ Stefani 1, 37126 Verona, Italy and ${ }^{2}$ Division of Endocrinology, Ospedale Sant'Andrea, University La Sapienza, Ospedale Sant'Andrea, Via Di Grotta Rossa \\ 1035, 00189 Rome, Italy \\ (Correspondence should be addressed to P Moghetti; Email: paolo.moghetti@univrit)
}

\begin{abstract}
Objective: In hyperandrogenic women, hyperinsulinaemia amplifies $17 \alpha$-hydroxycorticosteroid intermediate response to ACTH, without alterations in serum cortisol or androgen response to stimulation. The aim of the study is to assess whether acute hyperinsulinaemia determines absolute changes in either basal or ACTH-stimulated adrenal steroidogenesis in these subjects.

Design and methods: Twelve young hyperandrogenic women were submitted in two separate days to an $8 \mathrm{~h}$ hyperinsulinaemic $\left(80 \mathrm{mU} / \mathrm{m}^{2} \times \mathrm{min}\right)$ euglycaemic clamp, and to an $8 \mathrm{~h}$ saline infusion. In the second half of both the protocols, a $4 \mathrm{~h} \mathrm{ACTH}$ infusion $(62.5 \mu \mathrm{g} / \mathrm{h})$ was carried out. Serum cortisol, progesterone, 17 $\alpha$-hydroxyprogesterone (17-OHP), 17 $\alpha$-hydroxypregnenolone (17-OHPREG), DHEA and androstenedione were measured at basal level and during the protocols. Absolute adrenal hormone secretion was quantified by measuring C19 and C21 steroid metabolites in urine collected after the first $4 \mathrm{~h}$ of insulin or saline infusion, and subsequently after $4 \mathrm{~h}$ of concurrent ACTH infusion.

Results: During insulin infusion, ACTH-stimulated 17-OHPREG and 17-OHP were significantly higher than during saline infusion. No significant differences in cortisol and androgens response to ACTH were found between the protocols. Nevertheless, urinary excretion of ACTH-stimulated C19 and C21 steroid metabolites was significantly higher during hyperinsulinaemia than at basal insulin levels (both $P<0.005)$. Changes in steroid metabolites molar ratios suggested stimulation by insulin of $5 \alpha$-reductase activity.

Conclusions: These in vivo data support the hypothesis that insulin acutely enhances ACTH effects on both the androgen and glucocorticoid pathways.
\end{abstract}

European Journal of Endocrinology 164 197-203

\section{Introduction}

Although it is well known that hyperandrogenism is associated with hyperinsulinaemia, the mechanisms underlying this association remain largely unclear. In vitro studies have shown that insulin enhances the stimulatory effect of LH on androgen synthesis in the ovary (1). However, very few studies have explored the hypothesis that insulin could modulate adrenal steroidogenesis as well. This possibility is indirectly supported by the finding that in women with polycystic ovary syndrome (PCOS) there is often an increase in both ovarian and adrenal serum androgens (2) and by the different response of adrenal steroids to ACTH stimulation reported in hyperinsulinaemic versus normoinsulinaemic hyperandrogenic women (3).

Some in vitro studies have shown that insulin enhances basal and ACTH-stimulated steroidogenesis in human adrenocortical cells and induces the mRNA of steroidogenic enzymes in these cells (4). Furthermore, a reduction in adrenal androgens was observed in PCOS women treated with some drugs lowering plasma insulin, by interfering with insulin secretion or insulin sensitivity, such as somatostatin (5) or glitazones (6). However, this effect was not reported during treatment with diazoxide (7) or metformin (8). In addition, increased 17-hydroxycorticosteroid intermediate/ androgen ratios were reported during acute hyperinsulinaemia in healthy males, suggesting an inhibitory effect of insulin on 17,20-lyase activity (9).

We previously found that during a $3 \mathrm{~h}$ insulin infusion, $17 \alpha$-hydroxyprogesterone (17-OHP) and 17 $\alpha$-hydroxypregnenolone (17-OHPREG) responses to ACTH stimulation were enhanced in hyperandrogenic women, whereas serum androgen response was unaffected (10). Interestingly, these data in the adrenals mirror those observed after GNRH-agonist stimulation of the pituitaryovarian axis in hyperinsulinaemic PCOS women (2). 
As a whole, these findings suggest that insulin could exert similar regulatory effects on adrenal and ovarian steroidogenesis, determining a relative impairment of 17,20 -lyase activity in respect to $17 \alpha$-hydroxylase activity during stimulation with ACTH or LH respectively. However, it still remains unclear what functional consequences this action might have. In particular, we do not know whether hormonal alterations observed during acute hyperinsulinaemia are associated with relative or absolute changes in adrenal steroidogenesis.

In this study, we have assessed the effects of hyperinsulinaemia, obtained by an $8 \mathrm{~h}$ glucose clamp, on the androgen and glucocorticoid hormones production. This was estimated by measuring steroid metabolites excretion in fractionated urine samples, collected before and during ACTH stimulation.

\section{Materials and methods}

\section{Subjects}

Twelve young women, referred to the outpatient clinic of the Division of Endocrinology and Metabolism of the Verona Hospital - a tertiary care academic centre - for hyperandrogenic oligoamenorrhoea and/or hirsutism, were included in the study. According to the Rotterdam criteria (11) nine of these subjects had polycystic ovary syndrome (eight with the classic phenotype and one with the ovulatory phenotype). The remaining three subjects had idiopathic hirsutism. Late onset adrenal hyperplasia, Cushing's syndrome, thyroid dysfunction and hyperprolactinaemia were ruled out in all subjects. None of them suffered from any other diseases or were taking medications potentially interfering with the evaluation of the study.

The main characteristics of the subjects are reported in Table 1 . Ten patients had normal glucose tolerance and two, both with PCOS, had impaired glucose tolerance.

Table 1 Main characteristics of hyperandrogenic women under study (mean \pm s.D.).

\begin{tabular}{lc}
\hline Age (years) & $21.4 \pm 4.3$ \\
Body mass index $\left(\mathrm{kg} / \mathrm{m}^{2}\right)$ & $26.6 \pm 7.4$ \\
WHR & $0.81 \pm 0.08$ \\
Fasting plasma glucose $(\mathrm{mg} / \mathrm{dl})$ & $85.9 \pm 8.5$ \\
Fasting insulin $(\mathrm{mU} / \mathrm{l})$ & $18.2 \pm 11.5$ \\
$M$ 90-120 $(\mathrm{mg} / \mathrm{kg} \text { fat-free mass } \times \mathrm{min})^{\mathrm{a}}$ & $8.06 \pm 3.18$ \\
$M 120-240(\mathrm{mg} / \mathrm{kg} \text { fat-free mass } \times \mathrm{min})^{\mathrm{b}}$ & $9.56 \pm 3.00$ \\
LH $(\mathrm{IU} / \mathrm{l})$ & $9.3 \pm 6.5$ \\
FSH $(\mathrm{IU} / \mathrm{l})$ & $5.5 \pm 1.3$ \\
Total testosterone $(\mathrm{ng} / \mathrm{dl})$ & $77.8 \pm 49.0$ \\
DHEAS $(\mu \mathrm{g} / \mathrm{l})$ & $1831 \pm 728$
\end{tabular}

To convert glucose to $\mathrm{mmol} / \mathrm{l}$ multiply by 0.055 ; to convert testosterone to $\mathrm{nmol} / \mathrm{l}$ multiply by 0.0347 ; to convert DHEAS to $\mu \mathrm{mol} / \mathrm{l}$ multiply by 0.0026 . ansulin-stimulated glucose usage calculated in the $90-120$ min period of the clamp.

${ }^{\mathrm{b}}$ Insulin-stimulated glucose usage calculated in the 120-240 min period of the clamp.

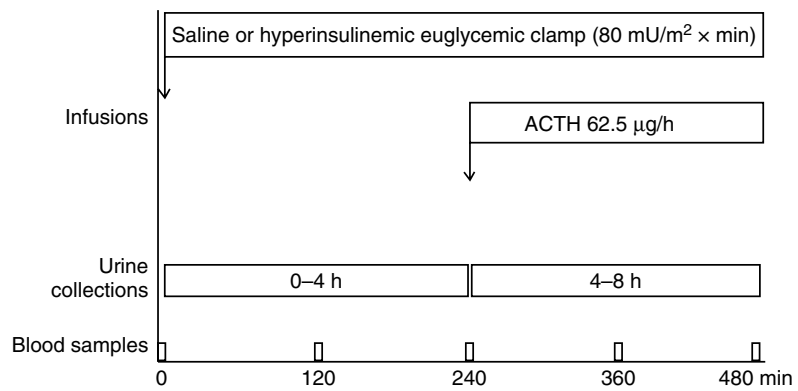

Figure 1 Study protocol.

All participants gave their informed consent to the study, which was approved by our institutional ethical committee and conducted according to the Helsinki Declarations.

\section{Study design}

Figure 1 shows the study protocol. To evaluate the in vivo effects of insulin on adrenal steroidogenesis all subjects were studied on two occasions, at basal and high insulin levels respectively. In these studies, saline or insulin infusion was carried out for $8 \mathrm{~h}$. During the insulin infusion protocol, plasma glucose was maintained at the basal levels by appropriately adjusting a concurrent i.v. glucose infusion, according to the euglycaemic hyperinsulinaemic clamp technique, as previously described (12). In this study, an insulin infusion rate of $80 \mathrm{mU} / \mathrm{m}^{2} \times$ min was chosen to reach serum insulin concentrations similar to those found in insulin-resistant subjects.

After the first $4 \mathrm{~h}$ of insulin or saline infusion, a concurrent i.v. infusion of ACTH-(1-24) (Synacthen, Ciba-Geigy, Basel, Switzerland) was started and maintained at $62.5 \mu \mathrm{g} / \mathrm{h}$ for the remaining $4 \mathrm{~h}$ to obtain a prolonged maximal stimulation of the adrenal steroidogenesis.

Blood samples were obtained at baseline and subsequently every $2 \mathrm{~h}$ till the end of the studies. In each study, fractionated urine collections were also obtained during the first $4 \mathrm{~h}$ period - in which insulin or saline alone was infused - and during the subsequent $4 \mathrm{~h}$ period - in which ACTH was also infused - to assess the whole adrenal hormone production through the gas chromatographic assays of C19 and C21 steroid metabolites.

All tests were performed at fasting in the morning. In non-amenorrhoeic subjects, the studies were carried out in the early follicular phase of the menstrual cycle. In each subject, the two tests were carried out with an interval of at least 3 days.

Serum samples were evaluated for insulin, cortisol, and intermediate metabolites of $\Delta 4$ (progesterone, 17-OHP, androstenedione) and $\Delta 5$ (17-OHPREG, DHEA) steroidogenic pathways. 
On each urine sample, the following were assayed: androsterone (A), etiocholanolone (E), 11-oxo-androsterone (11-oxoA), 11-oxo-etiocholanolone (11-oxoE), 11-hydroxyandrosterone (11-OHA), 11-hydroxyetiocholanolone (11-OHE), DHEA, tetrahydrocortisone (THE), tetrahydrocortisol (THF), allo-tetrahydrocortisol ( $\alpha \mathrm{THF})$, tetrahydrocorticosterone (THB), allo-tetrahydrocorticosterone ( $\alpha \mathrm{THB})$, tetrahydrodehydrocorticosterone (THA), $\alpha$ - and $\beta$-cortolone, $\alpha$ - and $\beta$-cortol.

Supplementary Figure 1 (see section on supplementary data given at the end of this article) shows the metabolic pathways concerning these metabolites.

\section{Assays}

Plasma glucose was measured by the glucose-oxidase method (Beckman Instruments, Inc., Palo Alto, CA, USA). Insulin was assayed with an immunoradiometric method (Medgenix Diagnostics SA, Fieurus, Belgium). DHEAS was measured by double antibodies RIA (RADIM, Pomezia, Rome, Italy). Progesterone and cortisol were evaluated with immunoenzymatic methods, using an ES analyzer (Boheringer Mannheim) and a kit by Abbott Laboratories respectively. Androstenedione and 17-OHP were measured by RIA methods (DSL, Webster, TX, USA; DPC, Los Angles, CA, USA); 17-OHPREG and DHEA were determined with an RIA method after ether extraction and celite microcolumn chromatography (BDH analytical Filter AID, BDH, Poole, UK), as previously described (13). All measurements were carried out in duplicate, and all samples from each subject were measured in the same assay. The intra-assay coefficients of variation (CV) were $<6.5 \%$ for all determinations.

Urinary steroid metabolites were measured by Schmidt's method (14), based on anion exchange chromatographic separation, purification on diethylaminoethyl-Sephadex A-25 microcolumns and final analysis of the individual steroids by capillary column gas-liquid chromatography (HPLC). Inter- and intraassay $\mathrm{CV}$ ranged $3-10$ and $3-8 \%$ respectively, for the single metabolites evaluated. In the urine samples, creatinine was determined by a colourimetric method (Integra 700 Analyzer, Roche Diagnostics). Urinary steroid metabolites measurements were corrected for the corresponding creatinine concentrations and were expressed as $\mathrm{mg} / \mathrm{mg}$ creatinine $\times 100$.

\section{Calculations}

To estimate the apparent activities of the main enzymes of androgen synthesis, several molar ratios between precursors and products were calculated in serum samples. In particular, 17-OHPREG/DHEA and 17-OHP/androstenedione molar ratios were calculated as indexes of 17,20-lyase activity; 17-OHPREG/17-OHP and DHEA/androstenedione ratios were calculated as indexes of $3 \beta$-hydroxysteroid dehydrogenase.
In the urinary samples, the sum (THE+THF $+\alpha \mathrm{THF}+\alpha$-cortol $+\beta$-cortol $+\alpha$-cortolone $+\beta$-cortolone) was calculated to estimate the whole cortisol production, and the sum $(\mathrm{A}+\mathrm{E}+11$-oxoA+11-oxoE $+11-\mathrm{OHA}+11-\mathrm{OHE}+\mathrm{DHEA})$ was calculated to estimate the whole androgen production. In addition, the ratios E/A, 11-OHE/11-OHA, THB/ $\alpha \mathrm{THB}$ and THF/ $\alpha \mathrm{THF}$ were calculated as indexes of $5 \alpha$-reductase activity, and the ratios $(11-\mathrm{oxoE}+11-\mathrm{oxoA}) /(11-\mathrm{OHE}+11-\mathrm{OHA})$, $\mathrm{THE} / \mathrm{THF}+\alpha \mathrm{THF}, \mathrm{THA} / \mathrm{THB}+\alpha \mathrm{THB}$ and $(\alpha-+\beta$-cortolone $) /(\alpha-+\beta$-cortol $)$ were calculated as indexes of $11 \beta$-hydroxysteroid dehydrogenase activity (11 $\beta$-HSD).

Insulin sensitivity was estimated by the insulininduced glucose usage in the clamp studies (' $M$ value'). This figure was calculated both in the customary 90-120 min and in the 120-240 min. The latter, a measure of insulin action when ACTH infusion was started, was used when insulin sensitivity was correlated with steroid responses to stimulation.

\section{Statistical analysis}

Student's $t$-test for paired data and ANOVA for repeated measures were used to compare the data obtained during saline and insulin infusions. Correlations between variables were made using simple regression analysis. Skewed variables were log-transformed before the analyses to ensure normality of data and then backtransformed to their natural units for presentation in tables and figures. Data are expressed as mean \pm s.D. in the text and in the tables, and as mean \pm s.E.M. in the figures. $P$ values $<0.05$ were considered statistically significant. Analyses were carried out using Statview 5.0.1 software (SAS Institute, Cary, NC, USA).

\section{Results}

\section{Serum hormones}

Serum insulin increased from $17.6 \pm 2.9$ to 235 $\pm 10.1 \mathrm{mU} / \mathrm{l}(P<0.0001)$ during the euglycaemic hyperinsulinaemic clamp, while it did not significantly change during the saline infusion $(18.7 \pm 3.8$ vs 12.0 $\pm 1.7 \mathrm{mU} / \mathrm{l})$. Plasma glucose during the clamp was similar to the value measured during the saline infusion $(89 \pm 8$ vs $84 \pm 4 \mathrm{mg} / \mathrm{dl}, P=\mathrm{NS})$. Mean insulin-stimulated glucose usage in the clamp studies (Table 1) indicated that these subjects were insulin resistant. However, individual values ranged widely. In particular, insulin sensitivity ranged from very low to low-normal in the PCOS women (4.7-12.2 $\mathrm{mg} / \mathrm{kg}$ fat-free mass $\times \mathrm{min})$, whereas it was around the lower limit of normal insulin sensitivity in the three subjects with idiopathic hirsutism (10.8-12.4 $\mathrm{mg} / \mathrm{kg}$ fat-free mass $\times \mathrm{min})$.

Basal serum cortisol, progesterone, 17-OHP, 17-OHPREG, androstenedione and DHEA were similar in the the protocols. After $4 \mathrm{~h}$ of insulin or saline 

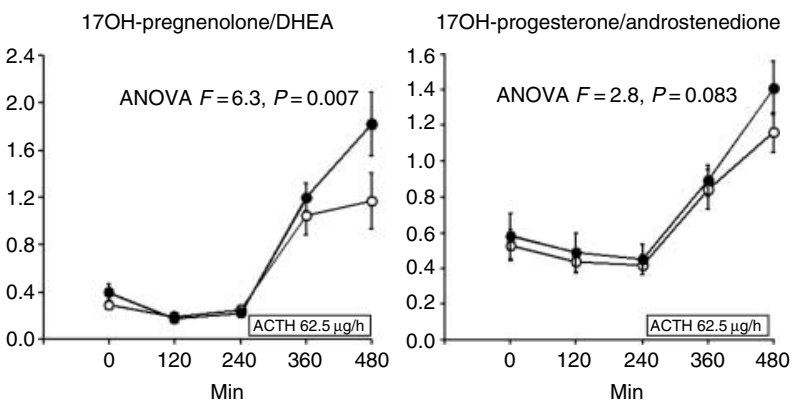

Figure 2 Molar ratios of $17 \mathrm{OH}$-pregnenolone/DHEA (left panel) and $17 \mathrm{OH}$-progesterone/androstenedione (right panel), indices of 17,20 -lyase activity, during insulin (black circles) and saline (white circles) infusion. $P$ refers to the difference in responses to ACTH infusion between the two studies.

infusion, before ACTH stimulation, serum concentrations of these hormones did not show statistically significant differences (Supplementary Figure 2, see section on supplementary data given at the end of this article).

As expected, ACTH stimulation determined a prompt increase in all serum steroids examined. ACTHstimulated levels of cortisol, progesterone, androstenedione and DHEA were again comparable during insulin and saline infusion. However, hyperinsulinaemia was associated with a more marked increase in 17-OHPREG $(P<0.001)$ and 17-OHP $(P=0.02)$ in comparison to control studies (Supplementary Figure 2).

Before ACTH stimulation, 17-OHP/androstenedione and 17-OHPREG/DHEA molar ratios, indexes of apparent 17,20-lyase activity, were similar during insulin or saline infusion (Fig. 2). After ACTH infusion, these ratios were higher during hyperinsulinaemia than at basal insulin levels - although the former did not reach statistical significance - suggesting an apparent inhibition of 17,20-lyase activity by insulin.

No significant difference in molar ratios indexes of $3 \beta$-hydroxysteroid dehydrogenase activity was observed between the two protocols, either before or after ACTH stimulation. Similar results were found when all these analyses were carried out in the nine PCOS women only, although minor changes occurred in the statistical significance level (data not shown).

\section{Urinary metabolites}

Table 2 shows urinary steroid metabolites during insulin or saline infusion, before and after ACTH stimulation. Before the stimulation, these metabolites were not significantly different between the protocols, except for minor differences in THE and 11-OHA, which were higher, and for 11-oxoE, which was lower during insulin infusion than during saline infusion. However, after ACTH stimulation, several urinary metabolites of both androgen and cortisol pathways - androsterone, etiocholanolone, 11-OHE, DHEA, THE, THF, cortolone showed a more pronounced increase during hyperinsulinaemia than at baseline insulin levels.

Before ACTH infusion, both the sum of cortisol metabolites and the sum of androgen metabolites were similar during the two protocols. However, during ACTH stimulation, both sums were significantly higher during hyperinsulinaemia than at basal insulin (Fig. 3).

Table 2 Urinary steroid metabolites excretion (mean \pm s.E.M.) measured before (0-240 min) and after ACTH stimulation (240-480 min) during saline or insulin infusion.

\begin{tabular}{|c|c|c|c|c|c|c|}
\hline \multirow[b]{2}{*}{$\begin{array}{l}\text { Urinary metabolites } \\
(\mathrm{mg} / \mathrm{mg} \text { creatinine } \times 100)\end{array}$} & \multicolumn{2}{|c|}{ Saline } & \multicolumn{2}{|c|}{ Insulin } & \multirow[b]{2}{*}{$F^{*}$} & \multirow[b]{2}{*}{$\boldsymbol{P}^{\star}$} \\
\hline & $0-240 \mathrm{~min}$ & $\begin{array}{l}240-480 \min \\
+ \text { ACTH }\end{array}$ & $0-240 \mathrm{~min}$ & $\begin{array}{l}240-480 \mathrm{~min} \\
+\mathrm{ACTH}\end{array}$ & & \\
\hline Androsterone (A) & $0.291 \pm 0.040$ & $0.341 \pm 0.040$ & $0.262 \pm 0.038$ & $0.415 \pm 0.048$ & 21.33 & 0.0007 \\
\hline Etiocholanolone (E) & $0.253 \pm 0.030$ & $0.314 \pm 0.036$ & $0.230 \pm 0.031$ & $0.345 \pm 0.042$ & 8.92 & 0.0124 \\
\hline 11-oxo-androsterone (11-oxoA) & $0.005 \pm 0.002$ & $0.009 \pm 0.003$ & $0.027 \pm 0.014$ & $0.007 \pm 0.003$ & 3.34 & 0.0949 \\
\hline 11-oxo-etiocholanolone (11-oxoE) & $0.067 \pm 0.011$ & $0.070 \pm 0.009$ & $0.036 \pm 0.013^{\dagger}$ & $0.030 \pm 0.010$ & 2.297 & 0.1578 \\
\hline 11-hydroxyandrosterone (11-OHA) & $0.122 \pm 0.018$ & $0.160 \pm 0.020$ & $0.158 \pm 0.023^{\dagger}$ & $0.214 \pm 0.027$ & 2.190 & 0.1670 \\
\hline 11-hydroxyetiocholanolone (11-OHE) & $0.029 \pm 0.005$ & $0.038 \pm 0.005$ & $0.024 \pm 0.005$ & $0.021 \pm 0.007$ & 5.554 & 0.0380 \\
\hline DHEA & $0.143 \pm 0.042$ & $0.191 \pm 0.055$ & $0.164 \pm 0.060$ & $0.505 \pm 0.148$ & 10.51 & 0.0078 \\
\hline Tetrahydrocortisone (THE) & $0.442 \pm 0.052$ & $0.535 \pm 0.048$ & $0.539 \pm 0.060^{\dagger}$ & $0.938 \pm 0.079$ & 26.80 & 0.0003 \\
\hline Tetrahydrocortisol (THF) & $0.187 \pm 0.025$ & $0.386 \pm 0.051$ & $0.211 \pm 0.030$ & $0.545 \pm 0.070$ & 6.608 & 0.0260 \\
\hline allo-tetrahydrocortisol ( $\alpha \mathrm{THF})$ & $0.215 \pm 0.030$ & $0.482 \pm 0.061$ & $0.233 \pm 0.033$ & $0.587 \pm 0.077$ & 1.280 & 0.2843 \\
\hline Tetrahydrocorticosterone (THB) & $0.031 \pm 0.005$ & $0.082 \pm 0.010$ & $0.036 \pm 0.005$ & $0.116 \pm 0.015$ & 4.865 & 0.0519 \\
\hline allo-tetrahydrocorticosterone ( $\alpha \mathrm{THB})$ & $0.040 \pm 0.013$ & $0.176 \pm 0.023$ & $0.040 \pm 0.012$ & $0.264 \pm 0.061$ & 1.840 & 0.2171 \\
\hline Tetrahydrodehydrocorticosterone (THA) & $0.029 \pm 0.004$ & $0.094 \pm 0.016$ & $0.024 \pm 0.005$ & $0.121 \pm 0.017$ & 1.862 & 0.2146 \\
\hline$\alpha$-cortolone & $0.179 \pm 0.015$ & $0.197 \pm 0.014$ & $0.190 \pm 0.017$ & $0.226 \pm 0.020$ & 5.230 & 0.0430 \\
\hline$\beta$-cortolone & $0.090 \pm 0.008$ & $0.113 \pm 0.011$ & $0.086 \pm 0.009$ & $0.117 \pm 0.006$ & 3.979 & 0.0714 \\
\hline$\alpha$-cortol & $0.024 \pm 0.002$ & $0.040 \pm 0.004$ & $0.028 \pm 0.004$ & $0.045 \pm 0.005$ & 0.005 & 0.9439 \\
\hline$\beta$-cortol & $0.035 \pm 0.004$ & $0.045 \pm 0.005$ & $0.025 \pm 0.005$ & $0.035 \pm 0.004$ & 2.193 & 0.1695 \\
\hline
\end{tabular}

${ }^{\star} F$ and $P$ values refer to comparisons between the protocols by repeated measures ANOVA; significant differences are in bold type. ${ }^{\dagger} P<0.05$ vs $0-240$ min during saline infusion. 

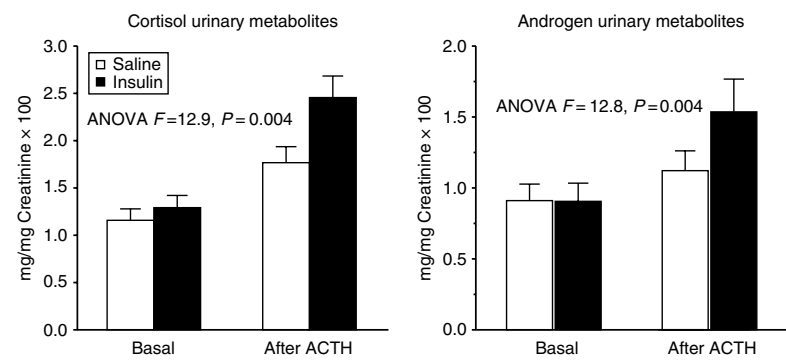

Figure 3 Sums of cortisol (left panel) and androgen (right panel) urinary metabolites, before and after ACTH stimulation, during insulin (black bars) and saline (white bars) infusion. $P$ refers to the difference in responses to ACTH infusion between the two studies.

As regards the urinary metabolite ratios, before ACTH the indexes of $5 \alpha$-reductase and $11 \beta-H S D$ activity showed no significant difference during insulin and saline infusion. Conversely, during ACTH stimulation, hyperinsulinaemia was associated with a more pronounced reduction in $\mathrm{E} / \mathrm{A}$ ratio $(F=9.9, P=0.009)$, suggesting stimulation by insulin of $5 \alpha$-reductase activity. No statistically significant difference in the indexes of $11 \beta$-HSD activity was observed between the insulin and the saline infusion protocols.

As regards urinary steroids and their ratios, similar data were found when analyses were carried out in the nine PCOS women only (data not shown).

\section{Correlations}

No significant correlation was observed between insulin levels and basal or ACTH-stimulated serum or urinary steroids. Similarly, no correlation was found between the insulin-sensitivity measures obtained by the clamp studies and these parameters. However, insulin sensitivity positively correlated with the insulin-induced increase in the 17-OHP/androstenedione ratio $(r=0.67, P=0.024)$, thus indicating a negative correlation with the apparent 17,20-lyase activity.

No significant correlation was observed between body mass index and serum or urinary steroids response to insulin, either before or after ACTH stimulation.

The sum of urinary metabolites of cortisol correlated with the sum of urinary metabolites of androgens either during insulin or saline infusion and either before or after ACTH stimulation $(r=0.63-0.86$, $P<0.03-0.001)$.

\section{Discussion}

This study has confirmed our previous findings that an acute increase in insulin levels is associated with an enhanced response of $17 \alpha$-hydroxysteroid intermediates to ACTH and that this effect is not associated with significant modifications of serum androgens and cortisol (10). Consequently, during hyperinsulinaemia,
17-OHP/androstenedione and 17-OHPREG/DHEA molar ratios were higher, suggesting a relative inhibition by insulin of 17,20-lyase activity. Interestingly, consistent with this hypothesis, the extent of differences in the 17-OHP/androstenedione ratio between insulin and saline protocols was significantly correlated with insulin sensitivity. This enzyme is the key regulatory activity of androgen synthesis and in humans it is more active on the $\Delta 5$ pathway, the preferential pathway of adrenal androgen synthesis. This could explain why the effect of insulin was more evident on this pathway.

However, the main novel finding of this study is the more marked increase during hyperinsulinaemia, than at baseline insulin levels, of several urinary steroids, with significantly increased sums of both androgen and cortisol urinary metabolites. These data support the hypothesis that insulin enhances the effects of ACTH on both these pathways.

Based on these data, we can hypothesise that i) insulin is a physiological activator of the adrenal steroidosynthesis both in the androgen and glucocorticoid pathways; ii) concurrent adaptive activation of adrenal hormones metabolism and clearance avoids an increase in serum adrenal hormones. The similar results we observed in the glucocorticoid and adrenal androgens pathways, and the correlation between the increases of cortisol and androgen metabolites in response to ACTH also suggests that hyperinsulinaemia activates the adrenal steroidogenesis at an early stage. However, an alternative explanation is a primary effect of insulin on the metabolic clearance of these hormones, followed by an adaptive increase in hormone production.

There are very few available data to distinguish between these hypotheses. Kerstens et al. (15) reported an increase in urinary free cortisol and cortisone, as well as of urinary metabolites of cortisol, without any changes of plasma cortisol and cortisone, in healthy men submitted to a $24 \mathrm{~h}$ low-dose hyperinsulinaemic clamp. Interestingly, no change was observed in insulinresistant type 2 diabetic subjects. In this study, androgens and the interaction between insulin and ACTH stimulation were not assessed. Furthermore, Nestler \& Kahwash (16) reported that the metabolic clearance of DHEA increased during insulin infusion in men, but not in healthy women. To the best of our knowledge, these are the only previous studies that have assessed the effects of insulin infusion on urinary excretion of adrenal steroid metabolites. No study has investigated the effects of insulin on the metabolic clearance of adrenal hormones in hyperandrogenic women. Interestingly, Holt et al. (17) showed that in men basal cortisol clearance negatively correlated with glucose clampderived measures of insulin sensitivity, thus suggesting a positive correlation with insulin levels.

Androgen and cortisol catabolism is mainly dependent on the activity of two enzymes, namely, $5 \alpha$-reductase and $11 \beta$-HSD. The former is responsible 
for conversion of testosterone to dihydrotestosterone (DHT) in androgen-dependent target tissues, and for reduction of cortisol to $5 \alpha$-dihydrocortisol in the liver; $11 \beta$-HSD acts as a reductase, converting cortisone to cortisol, in the liver and adipose tissue (type 1 isoform), whereas it acts as a dehydrogenase, inactivating cortisol to cortisone, in mineralocorticoid target tissues (type 2 isoform).

In this study, we have found a lower E/A ratio during hyperinsulinaemia, suggesting that insulin stimulated $5 \alpha$-reductase activity. However, we did not observe significant changes in other ratios, which reflect the same enzyme activity. The reasons for these different findings are not easily explained. Notably, similar discrepancies were reported in other studies (18). In this study, no significant effect of hyperinsulinaemia on $11 \beta$-HSD was found.

In the previously described study carried out in healthy males, a mild hyperinsulinaemia, obtained by the glucose clamp, was associated with a significant increase in $\alpha \mathrm{THF} / \mathrm{THF}$ ratio (15), suggesting a stimulation of $5 \alpha$-reductase by insulin. However, unlike our data, increases in urinary THF/THE and plasma cortisol/cortisone ratios were also reported, suggesting that hyperinsulinaemia may also reset $11 \beta$-HSD activity towards cortisol synthesis, at least in males.

Previous studies compared these ratios in PCOS and healthy women (19-24), although none of them assessed the effects of hyperinsulinaemia on these features. As a whole, these studies suggest an increased activity of $5 \alpha$-reductase in PCOS women.

Data concerning 11 $\beta$-HSD activity in these subjects are more controversial. Some authors have reported an increased enzyme activity in PCOS women, as compared to controls $(18,20,25)$. However, these findings were not confirmed by others $(19,22)$.

In conclusion, acute hyperinsulinaemia, in a range found in insulin-resistant subjects, enhances in vivo adrenal response to ACTH stimulation, with a concurrent increase in adrenal steroid hormone metabolism. In particular, insulin seems able to stimulate both the androgen and the glucocorticoid pathways, suggesting an effect on the early steps of adrenal steroidosynthesis. The apparent reduction in 17,20 lyase activity could be either a direct effect of insulin or an intrinsic adaptive mechanism, limiting adrenal androgen overproduction. Further research is needed to clarify whether the primitive site of insulin action is at the level of adrenal steroid synthesis or metabolism.

\section{Supplementary data}

This is linked to the online version of the paper at http://dx.doi.org/10. 1530/EJE-10-0782.

\section{Declaration of interest}

The authors declare that there is no conflict of interest that could be perceived as prejudicing the impartiality of the research reported.

\section{Funding}

This work was supported by academic grants from the University of Verona (fondi $60 \%$ ).

\section{References}

1 Barbieri RL, Makris A, Randall RW, Daniels G, Kristner RW \& Ryan KJ. Insulin stimulates androgen accumulation in incubations of ovarian stroma obtained from women with hyperandrogenism. Journal of Clinical Endocrinology and Metabolism 199662 904-910. (doi:10.1210/jcem-62-5-904)

2 Ehrmann DA, Barnes RB \& Rosenfield RL. Polycystic ovary syndrome as a form of functional ovarian hyperandrogenism due to dysregulation of androgen secretion. Endocrine Reviews 199516 322-353. (doi:10.1210/edrv-16-3-322)

3 Azziz R, Bradley EL Jr, Potter HD, Parker CR Jr \& Boots LR. Chronic hyperinsulinemia and the adrenal androgen response to acute corticotropin (1-24) stimulation in hyperandrogenic women. American Journal of Obstetrics and Gynecology $1995 \mathbf{1 7 2}$ 1251-1256. (doi:10.1016/0002-9378(95)91488-9)

4 Kristiansen SB, Endoh A, Casson PR, Buster JE \& Hornsby PJ. Induction of steroidogenic enzyme genes by insulin and IGF-I in cultured adult human adrenocortical cells. Steroids $1997 \mathbf{6 2}$ 258-265. (doi:10.1016/S0039-128X(96)00223-1)

5 Lanzone A, Fulghesu AM, Guido M, Cuccinelli F, Caruso A \& Mancuso S. Somatostatin treatment reduces the exaggerated response of adrenocorticotropin hormone and cortisol to $\mathrm{CRH}$ in polycystic ovary syndrome. Fertility and Sterility 199767 34-39. (doi:10.1016/S0015-0282(97)81852-3)

6 Ehrmann DA, Schneider DJ, Sobel BE, Cavaghan MK, Imperial J, Rosenfield RL \& Polonsky KS. Troglitazone improves defects in insulin action, insulin secretion, ovarian steroidogenesis, and fibrinolysis in women with polycystic ovary syndrome. Journal of Clinical Endocrinology and Metabolism $1997 \mathbf{8 2} 2108-2116$. (doi:10.1210/jc.82.7.2108)

7 Nestler JE, Barlascini CO, Matt DW, Steingold KA, Plymate SR, Clore JN \& Blackard WG. Suppression of serum insulin by diazoxide reduces serum testosterone levels in obese women with polycystic ovary syndrome. Journal of Clinical Endocrinology and Metabolism 198968 1027-1032. (doi:10.1210/jcem-68-6-1027)

8 Moghetti P, Castello R, Negri C, Tosi F, Perrone F, Caputo M, Zanolin E \& Muggeo M. Metformin effects on clinical features, endocrine and metabolic profiles, and insulin sensitivity in polycystic ovary syndrome: a randomized, double blind, placebocontrolled 6-month trial, followed by open, long term clinical evaluation. Journal of Clinical Endocrinology and Metabolism 2000 85 139-146. (doi:10.1210/jc.85.1.139)

9 Nestler JE, McClanahan MA, Clore JN \& Blackard WG. Insulin inhibits adrenal 17,20-lyase activity in man. Journal of Clinical Endocrinology and Metabolism 199274 362-367. (doi:10.1210/jc. 74.2.362)

10 Moghetti P, Castello R, Negri C, Tosi F, Spiazzi GG, Brun E, Balducci R, Toscano V \& Muggeo M. Insulin infusion amplifies $17 \alpha$-hydroxysteroids intermediates response to ACTH in hyperandrogenic women: apparent relative impairment of 17,20-lyase activity. Journal of Clinical Endocrinology and Metabolism $1996 \mathbf{8 1}$ 881-886. (doi:10.1210/jc.81.3.881)

11 The Rotterdam ESHRE/ASRM-Sponsored PCOS Consensus Workshop Group 2004. Revised consensus on diagnostic criteria and long-term health risks related to polycystic ovary syndrome (PCOS). Human Reproduction 2003 19 41-47. (doi:10.1093/ humrep/deh098)

12 DeFronzo RA, Tobin JD \& Andres R. Glucose clamp technique: a method for quantifying insulin secretion and resistance. American Journal of Physiology 1979237 E214-E223. 
13 Balducci R, Boscherini B, Mangiantini A, Morellini M \& Toscano V. Isolated precocious pubarche: an approach. Journal of Clinical Endocrinology and Metabolism 199479 582-589. (doi:10.1210/ jc.79.2.582)

14 Schmidt NA, Borburgh HJ, Penders TJ \& Weykamp CW. Steroid profiling - an update. Clinical Chemistry $198531637-639$.

15 Kerstens MN, Riemens SC, Sluiter WJ, Pratt JJ, Wolthers BG \& Dullaart RPF. Lack of relationship between $11 \beta$-hydroxysteroid dehydrogenase setpoint and insulin sensitivity in the basal state and after $24 \mathrm{~h}$ of insulin infusion in healthy subjects and type 2 diabetic patients. Clinical Endocrinology 200052 403-411. (doi:10.1046/j.1365-2265.2000.00975.x)

16 Nestler JE \& Kahwash Z. Sex-specific action of insulin to acutely increase the metabolic clearance rate of dehydroepiandrosterone in humans. Journal of Clinical Investigation 199494 1484-1489. (doi:10.1172/JCI117487)

17 Holt HB, Wild SH, Postle AD, Zhang J, Koster G, Umpleby M, Shojaee-Moradic F, Dewbury K, Wood PJ, Phillips DI \& Byrne CD. Cortisol clearance and associations with insulin sensitivity, body fat and fatty liver in middle-aged men. Diabetologia $2007 \mathbf{5 0}$ 1024-1032. (doi:10.1007/s00125-007-0629-9)

18 Tsilchorozidou T, Honour JW \& Conwey GS. Altered cortisol metabolism in polycystic ovary syndrome: insulin enhances $5 \alpha$-reduction but not the elevated adrenal steroid production rates. Journal of Clinical Endocrinology and Metabolism $2003 \mathbf{8 8}$ 5907-5913. (doi:10.1210/jc.2003-030240)

19 Stewart PM, Shackleton CHL, Beastall GH \& Edwards CRW. $5 \alpha$-reductase activity in polycystic ovary syndrome. Lancet 1990 335 431-433. (doi:10.1016/0140-6736(90)90664-Q)

20 Rodin A, Thakkar H, Taylor N \& Clayton R. Hyperandrogenism in polycystic ovary syndrome. Evidence of dysregulation of $11 \beta$-hydroxysteroid dehydrogenase. New England Journal of Medicine 1994330 460-465. (doi:10.1056/NEJM199402173300703)
21 Chin D, Shackleton C, Prasad VK, Kohn B, David R, Imperato-McGinley J, Cohen H, McMahon DJ \& Oberfield SE. Increased $5 \alpha$-reductase and normal $11 \beta$-hydroxysteroid dehydrogenase metabolism of $\mathrm{C} 19$ and $\mathrm{C} 21$ steroids in a young population with polycystic ovarian syndrome. Journal of Pediatric Endocrinology and Metabolism 200013 253-259.

22 Vassiliadi DA, Barber TM, Hughes BA, McCarthy MI, Wass JAH, Franks S, Nightingale P, Tomlinson JW, Arlt W \& Stewart PM. Increased $5 \alpha$-reductase activity and adrenocortical drive in women with polycystic ovary syndrome. Journal of Clinical Endocrinology and Metabolism 200994 3558-3566. (doi:10. 1210/jc.2009-0837)

23 Frassnacht M, Schlenz N, Schneider SB, Wudy SA, Allolio B \& Arlt $W$. Beyond adrenal and ovarian androgen generation: increased peripheral $5 \alpha$-reductase activity in women with polycystic ovary syndrome. Journal of Clinical Endocrinology and Metabolism $2003 \mathbf{8 8}$ 2760-2766. (doi:10.1210/jc.2002021875)

24 Glintborg D, Hermann PA, Hagen C, Thorbjorn Jensen L, Frystyk J, Bennett P, Flyvbjerg A \& Andersen M. A randomized placebocontrolled study on the effects of pioglitazone on cortisol metabolism in polycystic ovary syndrome. Fertility and Sterility 200991 842-850. (doi:10.1016/j.fertnstert.2007.12.082)

25 Luppa P, Muller B, Jacob K, Kimmig R, Strowitzki T, Hoss C, Weber MM, Engelhardt D \& Lobo RA. Variations of steroid hormone metabolites in serum and urine in polycystic ovary syndrome after nafarelin stimulation: evidence for an altered corticoid excretion. Journal of Clinical Endocrinology and Metabolism 199580 280-288. (doi:10.1210/jc.80.1.280)

Received 25 October 2010

Accepted 8 November 2010 